\title{
On the role of Prognostics and Health Management in advanced maintenance systems
}
A. J. Guillén ${ }^{a^{*}}$, A. Crespo ${ }^{\text {a }}$, M. Macchi ${ }^{\mathrm{b}}$, J. Gómez $^{\mathrm{a}}$
${ }^{a}$ Department of Industrial Management, School of Engineering, University of Seville, Camino de los Descubrimientos s/n, Sevilla, Spain;

${ }^{b}$ Department of Management, Economics and Industrial Engineering, Politecnico di Milano, Piazza Leonardo Da Vinci 32, Milano, Italy.

*Antonio J. Guillén (corresponding author)

ajguillen@us.es

+34654152067

Adolfo Crespo

adolfo@etsi.us.es

+34954487215

Marco Macchi

marco.macchi@polimi.it

Juan Fco. Gómez

juan.gomez@iies.es

+34954487215

\section{Acknowledgement}

This research work was performed within the context of SustainOwner ('Sustainable Design and Management of Industrial Assets through Total Value and Cost of Ownership'), a project sponsored by the EU Framework Programme Horizon 2020, MSCA-RISE-2014: Marie Skłodowska-Curie Research and Innovation Staff Exchange (RISE) (grant agreement number 645733 - Sustain-Owner - H2020-MSCA-RISE2014). 


\section{Abstract}

The advanced use of the Information and Communication Technologies is evolving the way that systems are managed and maintained. A great number of techniques and methods have emerged in the light of these advances allowing to have an accurate and knowledge about the systems' condition evolution and remaining useful life. The advances are recognized as outcomes of an innovative discipline, nowadays discussed under the term of Prognostics and Health Management (PHM). In order to analyze how maintenance will change by using PHM, a conceptual model is proposed built upon three views. The model highlights: (i) how PHM may impact the definition of maintenance policies; (ii) how PHM fits within the Condition Based Maintenance (CBM) and (iii) how PHM can be integrated into Reliability Centered Maintenance (RCM) programs. The conceptual model is the research finding of this review note and helps to discuss the role of PHM in advanced maintenance systems.

Keywords: PHM, RCM, maintenance policies, proactive maintenance, CBM. 


\section{Introduction}

Under the term of Prognostics and Health Management (PHM) a body of knowledge is included that nowadays is considered as an engineering discipline (Petch 2008, Cheng et al. 2010). This covers all methods and technologies to assess the reliability of a product in its actual life cycle conditions to determine the advent of failures, and mitigate system risks (Haddad et. al, 2012). Not only prognostics, but also detection and diagnosis of failures are problems addressed by the key skills of this discipline, along with the issues related to the subsequent use of the resulting information (in maintenance, logistics, life cycle control, asset management, etc.). Therefore, the skills are required by the necessities of the entire process, from data collection to interpretation in decision-making (Bird et al. 2014). Besides, PHM development and use is linked to Information and Communication Technologies (ICTs) development and its applications inside the maintenance function. It is then interesting to understand the role of PHM in the modern maintenance systems, in particular its contribution to more proactive approaches that allow reaching operational excellence in manufacturing companies.

With the fierce pressure companies are facing, it is nowadays more difficult to compete. Remaining competitiveness, especially in high tech sectors, requires continuous incorporation of new advances - with higher requirements, among others, of reliability while optimizing operation and maintenance. Indeed, reliability and maintenance have an increasingly important role in modern engineering systems and manufacturing processes (Pinjala et al 2011), which are becoming increasingly complex and are operating in a highly dynamic environment (Lee et. al 2011). Waeyenbergh and Pintelon (2002) claim that, in the case of leading-edge systems, characterized by a large number of technical items with great interaction level between them, maintenance is now more important than ever for business goals, not only in terms of cost reduction but regarding decisive contribution to company's performance and efficiency as part of an increasingly integrated business concept. Considering the maintenance department, Macchi and Fumagalli (2013) remark the importance of maintenance for the competitiveness of manufacturing companies and, in this regard, assess the maturity of its processes in terms of managerial, organizational and technological capabilities; especially looking at the technological capability, the maintenance objective is to adopt new technologies and tools in the company's practice to effectively contribute to competitiveness. In short, Takata et al. (2004) claim the importance for more efficient maintenance as a key for sustainability and competitiveness of enterprises and production systems, associating the decisionmaking process with the so called "eco-efficiency" of the production systems: this is an even more comprehensive view of the maintenance role, since eco-efficiency encompasses both the impact on business and on environment. Under this perspective, emphasis on the life cycle of manufacturing assets has caused a redefinition of the role of maintenance as "a prime method for life cycle management whose objective is to provide society with the required functions while minimizing material and energy consumption" (Takata et al., 2004). On the whole, the changes undergoing for the maintenance function are aligned with the transformation of the current manufacturing models based on the old paradigm of "unlimited resources and unlimited world's capacity for regeneration" 
towards a sustainable manufacturing (Garetti and Taisch, 2012). Along this vision, manufacturing will be strongly affected by sustainability issues and, what is relevant for the discussion in this paper, "technology, on which the manufacturing is largely based, is asked to give the tools and options for building new solutions towards a sustainable manufacturing concept" (Garetti and Taisch, 2012).

PHM will play its role, as it is fundamental in current evolution of maintenance function towards advanced maintenance systems. PHM, along with other trends like Emaintenance - term that serves as conceptual support to general use and applications of ICTs in maintenance (Muller et. al 2008) - appear as the key factors in achieving higher maintenance efficiency levels and life cycle cost reduction (Ly et al. 2009, Lee et. al 2006). The current perspective, established within the PHM discipline, can be considered complementary to the vision drawn by E-maintenance, well synthesized by the conceptual framework provided in (Levrat et al., 2008) with a focus on manufacturing application. This framework facilitates understanding of E-maintenance, by an acknowledgement of its potential through new services, processes, organisation and infrastructure; nonetheless, its contribution is focused on structuring of the technological discipline represented by E-maintenance, without discussing the specific techniques and methods required to fulfill the goals envisioned for the maintenance business functions and processes in future manufacturing. Nowadays, this gap can be completed by the evolution supported thanks to development of PHM discipline.

It is, however, necessary to understand the implications of PHM on maintenance and how to apply the PHM techniques and methods conveniently into a methodological framework for a system maintenance management. Until this moment the PHM research efforts have been focused on technological issues (models, methods and algorithms) and their application on very particular system (Lee et al 2011), while further discussions with respect to the introduction of PHM into a framework for a system maintenance management are still missing.

In this regard, we believe that there are currently two relevant challenges for the effective design, implementation and use of PHM solutions in advanced maintenance systems. First of all, the technical profiles, with new skills and capabilities, are far from those that can be found in traditional maintenance engineers or technicians. This is deeply discussed in Bird et al. (2014) who introduce how PHM is a multidisciplinary domain that is undergoing rapid evolution especially in the type of demanded skills and capabilities. The industry will then require highly qualified professionals, combining an initial training in PHM techniques and methods with specific expertise in this field; in regard to the work organization, the necessity of simultaneous use of different skills and capabilities - with high-level knowledge and expertise - will also have to be integrated in maintenance work-teams.

The second main challenge can be directly related to the original discussions on PHM, leading to focus the research efforts on models, methods and algorithms, while missing the management of their potential within a complex engineering system. Hence, it is worth remarking that the maintenance policies design have not been enough studied after considering the potential of PHM solutions. This challenge is addressed by this paper. Therefore, to effectively introduce PHM in the maintenance function, it is worth 
considering the existence of different, and well known, frameworks or methodologies that facilitate the design and implementation of maintenance policies.

Some examples of frameworks are RCM II (Moubray, 1997), CIBOCOF (Waeyenberg \& Pintelon 2009) or MGM-8PH (Crespo 2006). Although these frameworks consider the Condition Based Maintenance (CBM), none specifically includes the treatment of PHM techniques and methods and the capabilities that it brings to the maintenance function (Guillen et al 2014). This is largely owing to the fact that most used frameworks were developed prior to the recent growth of PHM. So, approaches are needed in order to addressing the formal use of PHM within maintenance policies, including as key aspect the integration with these mentioned frameworks which are, in industrial practice, reference tools for designing such policies.

In this sense, the RCM is one of the main references. Its main drawback is that it is a complex and costly implementation methodology, which causes its application is limited to equipment or industries with high tech/high risk (Waeyenberg \& Pintelon 2002) or, in other words, with high criticality (Crespo et al. 2015). Nevertheless, even in cases where its full implementation is not advisable, the foundations of its analysis are used as reference for obtaining simpler and more practical maintenance models (Waeyenberg and Pintelon 2002). Therefore, as a step towards a practical approach to the integration of PHM in maintenance policies, this paper is analyzing how to introduce the PHM within the RCM program, conceived in its simpler and practical versions.

The paper is organized as follows. Section 2 introduces PHM. Section 3 reflects on the link of PHM with maintenance, taking into account its impact on the design of maintenance policies and its relationship with different types of maintenance. Section 4 proposes the integration of PHM within a RCM program. Section 5 presents a case study with the purpose to provide a concrete illustration in real industrial setting of the concepts herein discussed. Eventually, Section 6 contains the conclusions.

\section{Introduction to PHM}

In recent decades traditional maintenance models, that combine run-to-failure (RTF) and time based preventive maintenance (TBM), are transforming to more proactive types in most industrial sectors, owing to CBM (Jardine et al 2006). In this evolution, PHM is considered one of the key factors to achieve system-level efficient maintenance and reduce life cycle costs (Ly et al. 2009). Prognosis research field is in fact promising new capabilities to improve the reliability of systems, leveraging both on design and maintenance along the useful lives (Sun et al 2012, Vatchsevanos 2006). Besides, PHM provides capabilities to achieve more proactivity in maintenance: in this regard, it is worth remarking that, as expectation for the future, the equipment data will be transformed by PHM solutions into valuable information to help not only maintenance managers, but also plant managers for optimizing planning, saving cost, and minimizing equipment downtimes (Lee et al., 2014).

In order to effectively grasp the evolution, it is worth reflecting on the general understanding owing to the terminology currently adopted (Section 2.1), before looking at PHM in its process model (Section 2.2) and role for competitiveness of enterprises (Section 2.3). 


\subsection{General understanding of PHM}

PHM has been generically understood as the process of determining the current state of a system in view of reliability and prediction of its future state. This is possible by combining the detection and interpretation of different parameters, i.e. environmental, operational and performance parameters, necessary for assessing the health state of the system and for predicting the remaining useful life (RUL) (Zio, 2010).

The rapid development of PHM techniques and methods, and their applications, is leading to the perception of PHM as engineering discipline (Sun et al. 2012) based on the use of in-situ monitoring and advanced methods for assessing degradation trends of a system and determining the RUL. This further allows to know the state of the system in relation to its life cycle and, thus, to control the risk level with which the system operates.

Haddad et al. (2012) present PHM as a discipline that allows different uses: i) evaluating the reliability of products in each stage of their life cycle; ii) determining the possible failures occurrence and the levers for risk reduction; iii) highlighting the RUL estimation to provide accurate lead-time estimation for maintenance implementation, that finally allows greater proactivity within an organization. Lee et al. (2011) add that PHM provides information to aid in making scheduled maintenance, or even autonomously triggered maintenance (i.e. self-maintenance); moreover, they mention asset management decisions or actions, even if they limit to advantages mostly related to maintenance management, such as the elimination of unnecessary and costly preventive maintenance, the optimization of maintenance scheduling, and the reduction of lead-time for spare parts and resources.

PHM can be understood also based on the related performance measures. Besides RUL, others terms as ETTF or PD appear in the literature. Estimated Time To Failure (ETTF) is a term equivalent to RUL, that is included and defined by ISO 18331. Another concept that should be considered regarding PHM solutions and their practical use to enable proactivity is the Prognostic Distance (PD). Sandborn and Wilkinson (2007) define PD as the time interval of an organization's ability to gather information necessary to predict a failure and forecast a future failure for taking (planning and implementing) appropriate actions. Thus, this term is closely linked with maintenance actions planning and execution, while RUL is only related to failure evolution: if $\mathrm{RUL}<\mathrm{PD}$, in a particular moment, the organization would not been able to trigger any maintenance action to prevent the failure. Fritzsche et al. (2014) present an interesting case study applied to aircraft logistics maintenance to understand PD concept and its scope.

A more comprehensive view is introduced by Saxena et al. 2010, who focus their attention on the performance measurement of prognostics algorithms. This is one of the major problem for PHM practical deployment: it is not enough developing prognostics methods, it is also essential evaluating and comparing their performances. Hence, they present a general framework, claiming that they define the most relevant time indexes with the purpose "to denote important events in a prognostic process". This allows not only to develop PHM solutions that calculate the RUL within given probabilistic uncertainty estimates, but also to introduce other relevant concepts for understanding and utilizing the developed solutions. Above all, it is worth remarking the proposal of a terminology to apply metrics for a standardized performance evaluation. 


\subsection{The process model of PHM}

PHM solutions implicitly covers a complete process (Figure 1), from capturing the raw data up to utilizing the information for decision-making (in maintenance, logistics, life cycle control, equipment design, etc.). This process has been originally conceived by ISO 13374, a standard that has been adopted within OSA-CBM (MIMOSA, 2006): today, ISO 13374/OSA-CBM are jointly being used as main international references for designing particular solutions and general software applications development (United States Army, 2013).

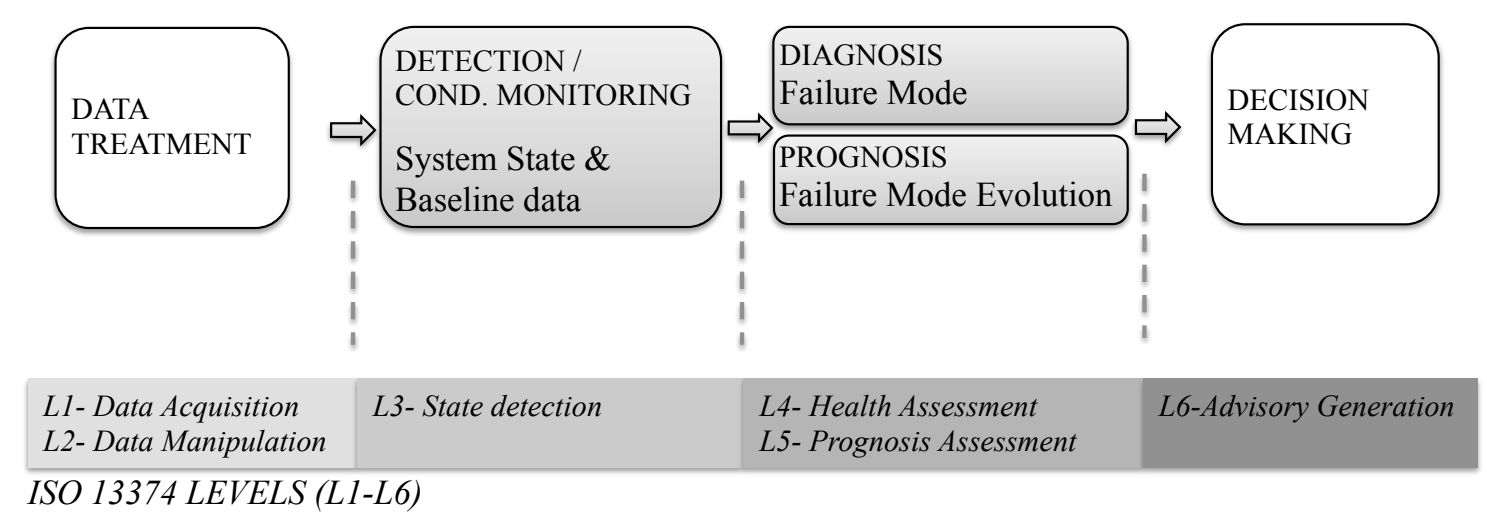

Figure 1. "From data to business value" process and detection, diagnosis and prognosis problems. Correlation with levels of ISO 13374

Often, the different phases of the process are difficult to interpret and distinguish. Along these phases, the detection, diagnosis and prognosis are the core issues addressed to develop the PHM solutions. Although the scientific literature treats these three issues separately, they are closely connected. So, for example, in most cases prognosis requires prior detection and diagnosis (Saxena et. al 2010). Assuming another perspective, the detection, diagnosis and prognosis can be considered complementary interpretations of the same gathered data from the system. On the whole, most of techniques and skills that are required when implementing the PHM solutions are similar, or even the same type, so it makes sense to consider the PHM process model as an expression of a unique engineering discipline.

Owing to the fact that an accurate definition of the PHM terms is complicated and, currently, there is no unique standardized and accepted vocabulary within the technical community, it is worth proposing a detailed definition of the core phases of the process, providing an operational perspective.

\section{Detection/Condition Monitoring}

It focuses on the state of the machine, equipment or system for which PHM is being developed. It enables to distinguish anomalous behaviors, comparing gathered data against baseline parameters (ISO 13379), and detecting and reporting abnormal events. In other words, the observed symptoms are related with reference behaviors to determine the condition or state of the system, therefore detecting the abnormality when it happens. This is defined as CM (Condition Monitoring) by ISO 13379 and SD (State Detection) by ISO 13374. Alerts and alarms management is also related with the detection phase. Besides, the operational context determination (current operational state and operational 
environment) has also to be considered within detection. For what concern performances, one of the detection objectives is to achieve the minimization of false positives and false negatives (Vatchsevanos et al 2006).

Diagnosis

It focuses on the failure modes and its causes. In particular, the ISO 13372 defines diagnosis as the result of diagnostic process, and this as the determination of the "nature" of the failure. This definition can be completed considering the two different stages in the diagnostic process within a complex engineering system:

- Isolation: it determines which component, or more accurately, which failure mode is affecting the behavior of the system;

- Identification: it determines or estimates the nature (or causes) and the extent (size and time) of the failures.

Besides, there are two different timings for obtaining the diagnosis:

- Before the failure occurs: it corresponds to the diagnosis of incipient failure modes; this enables to prevent the failure and is closely related with prognostic process;

- After the failure occurs: once the failure happens, the failure should be located accurately and as soon as possible, in order to minimize the MTTR (Mean Time to Repair); in this case, the diagnosis can improve the system maintainability and availability, especially if complex engineering system are considered, with a great level of interaction between system and components.

Some authors consider detection as a part of diagnosis (Vatchsevanos et al 2006), interpreting DII (detection, isolation \& identification) as the three diagnostic phases or diagnosis component. In the interpretation provided by this paper, diagnosis (as Isolation $\&$ Identification) is separated from detection owing to two reasons: i) detection/condition monitoring techniques and methods could be used by both the other process phases, diagnosis and prognosis; ii) detection/condition monitoring should be implemented before proceeding with any other process phase.

Prognosis

Prognosis is focused on failure mode evolution. The estimation of future behavior of the defined failure mode then allows failure risk assessment and control.

There are different types of outputs from various prognostic algorithms. Some algorithms assess Health Index (HI) or Probability of Failure (PoF) at any given point in time, and others carry out an assessment of the RUL based on a predetermined Failure Threshold (FT) (Saxena et. al 2010). An interesting aspect to analyze is the different prognostics approaches. Most authors distinguish three basic groups of methods, or approaches, for the prognosis: model-based prognostics, data-driven prognostics, and hybrid prognostics (Lee et al 2006, Petch y Jaai 2010).

For what concern performances, the prognosis objectives depend on many factors - time and cost for problem mitigation, system criticality, cost of a failure ...- , and can be related to the minimization of false positives and false negatives (Saxena et. al 2010).

\subsection{The role of $\mathrm{PHM}$ for competitiveness}

What is the role of PHM for competitiveness? Why is PHM believed to have high potential for competitive operations? These questions drive the review of this section, 
extending the discussion of the introduction on maintenance for competitiveness. There are many references that highlight the importance of incorporating new technologies along with diagnosis and prognosis capabilities - in others words, of implementing the CBM supported by PHM solutions -, as those levers that can promote a most room for improvement. This review highlights a selected number of cases, ranging from complex products/systems to infrastructures and manufacturing plants; this is then a demonstration of PHM potential in different business context dealing with highly engineered systems.

Vacthsevanos (2006) uses the term CBM/PHM to represent a new and more powerful CBM (diagnostic and prognostic-enabled CBM), and treats in depth how the area of intelligent maintenance and CBM/PHM of machinery is a vital one for today's complex systems in industry, such as aerospace vehicles, military and merchant ships, automobiles, etc. A major motivation for these developments is the realization that a more powerful CBM is needed to fully reap the benefits of new logistics support concepts, considering the maintenance impact on operations and logistics management.

Jardine et al (2006) focuses on the industry trend to higher cost of preventive maintenance, which has become one of major expenses of many companies. According to Jardine, this is owing to two effects related with rapid technological development: products/systems are more and more complex while the requirements (quality, reliability, etc.) are higher and subjected to a great variability and dynamic changes. More efficient maintenance approaches, such as CBM, are claimed to handle the rapid technological development with cost effectiveness.

In Gómez et al. 2012, the case of the use of ICTs for asset management on network utilities is analyzed. This may be considered as an example providing a business context currently featuring an high level of integration of ICTs jointly with the inherent problems as physical dispersion of the facilities and availability requirements in terms of customers demand (of a no-interruption service): in this context, a great impact can be expected by using advanced methods based on CBM and E-maintenance.

Focusing more specifically on manufacturing plants, two cases are worth of a citation. Maletič et. al (2014) proposes a study that aims to identify the improvement areas of maintenance in relation with their contribution to the profitability of companies. A method of analysis is proposed and a practical case study applied to the textile industry is presented. They conclude that practices related with advanced CBM are introducing the most potential for improvement. Macchi et al. (2014) propose a case study in the same industry regarding the investment in E-maintenance solutions developed in the frame of a Supervisory Control and Data Acquisition (SCADA): owing to the study, they underline the link between E-maintenance and CBM as an evidence of the fact that advanced ICT solutions are being adopted in manufacturing to progressively change the maintenance management process, in particular its policies. To this concern, they remark that the automation for controlling the plant's utilities and production lines can become a means to engineer "value" driven solutions based on advanced CBM services available by the plant.

Back to a more generic perspective of the role of PHM for competitiveness, it is worth focusing on "value" as concept for expressing the PHM potential for business. Haddad et al. (2012) compare the "value" of different types of maintenance (Figure 2). 
They depict the system health as a function of time (top diagram drawn in Figure 2) inspired in the P-F interval graphics used by classical CBM applications. System health, i.e. the ability of a system to perform its intended functionality, degrades over time and can be managed through maintenance decisions. The goal is to maximize the value of maintenance decisions through time (the bottom diagram of Figure 2): the most value is provided by CBM/PHM, as advanced evolution of classic CBM, while corrective maintenance (unscheduled maintenance) is the least value option; scheduled preventive maintenance has a low value if the time or usage to failure is not well characterized, because it wastes substantial part of the actual useful life.

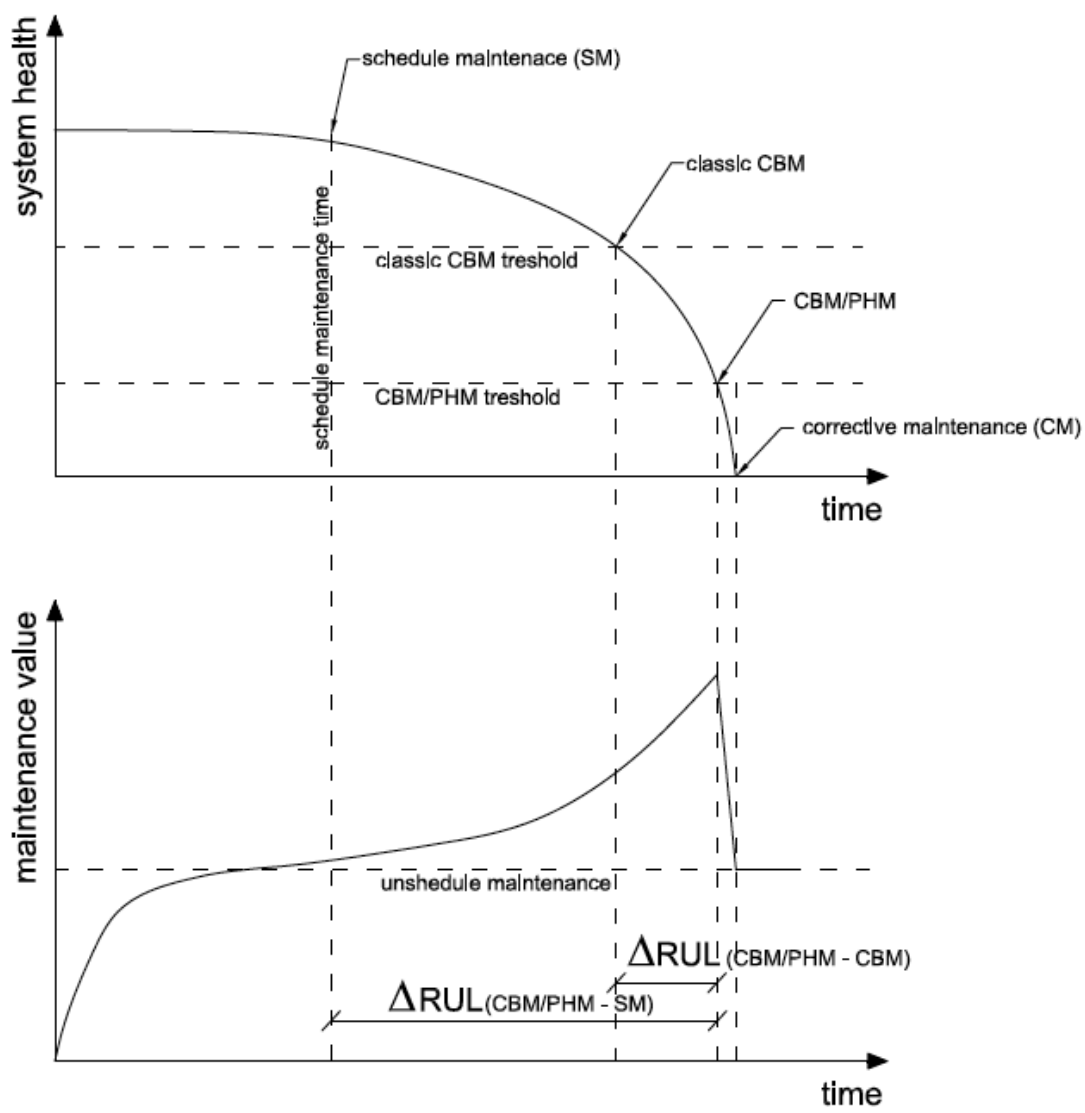

Figure 2. Value analysis of different maintenance options (Haddad et. al 2012)

Drawing upon this conceptual perspective of CBM/PHM, it can be concluded that improving maintenance through incorporation of techniques for the study of the condition is a major factor for the competitiveness of companies, being CBM programs, enabled by PHM, often considered to be the paradigm with the highest value, as it minimizes the unused RUL, avoids catastrophic failures, and presents a proper lead-time for logistics management (Haddad et al. 2012). A good example of this approach of the role of CBM and PHM is the ADS-79D-HDBK standard (US Army Aircraft 2013), where CBM is established as priority type of maintenance and provides guides on the use of PHM techniques and methods for the main systems and equipment present in an aircraft.

However, it is necessary to emphasize that, for an optimum design of maintenance policies of complex systems, CBM is combined with other maintenance options. In fact, $\mathrm{CBM}$ is not always the best type of maintenance, especially from the perspective of cost 
effectiveness: when failures of machines or components are not critical, we can even allow Run-To-Failure (RTF); when the lives of machines or components can be estimated precisely, scheduled TBM (Time Based Maintenance) is the most effective means of maintenance (Takata et al 2004); besides, as CBM/PHM opens opportunities to develop the Predictive Maintenance (PdM) policy as CBM evolution (Lee et al., 2011), (Lee et al. 2014), a good balance should be found between CBM and PdM.

Now that it has been discussed the role in the "traditional" scope of maintenance management, a further issue is worth of consideration, extending to visions for the future currently drawn by literature. The specific sub-question driving the search could be the following: is the role of PHM for competitiveness limited only to maintenance function? Based on recent references, it can be asserted that the benefits of prognosis and, by extension, of PHM will go beyond the maintenance function as classically conceived.

PHM application is the foundation for important improvements in all phases of the system lifecycle (Sun et al. 2012). In Figure 3 different life cycle phases, and benefits of every phase, are depicted.

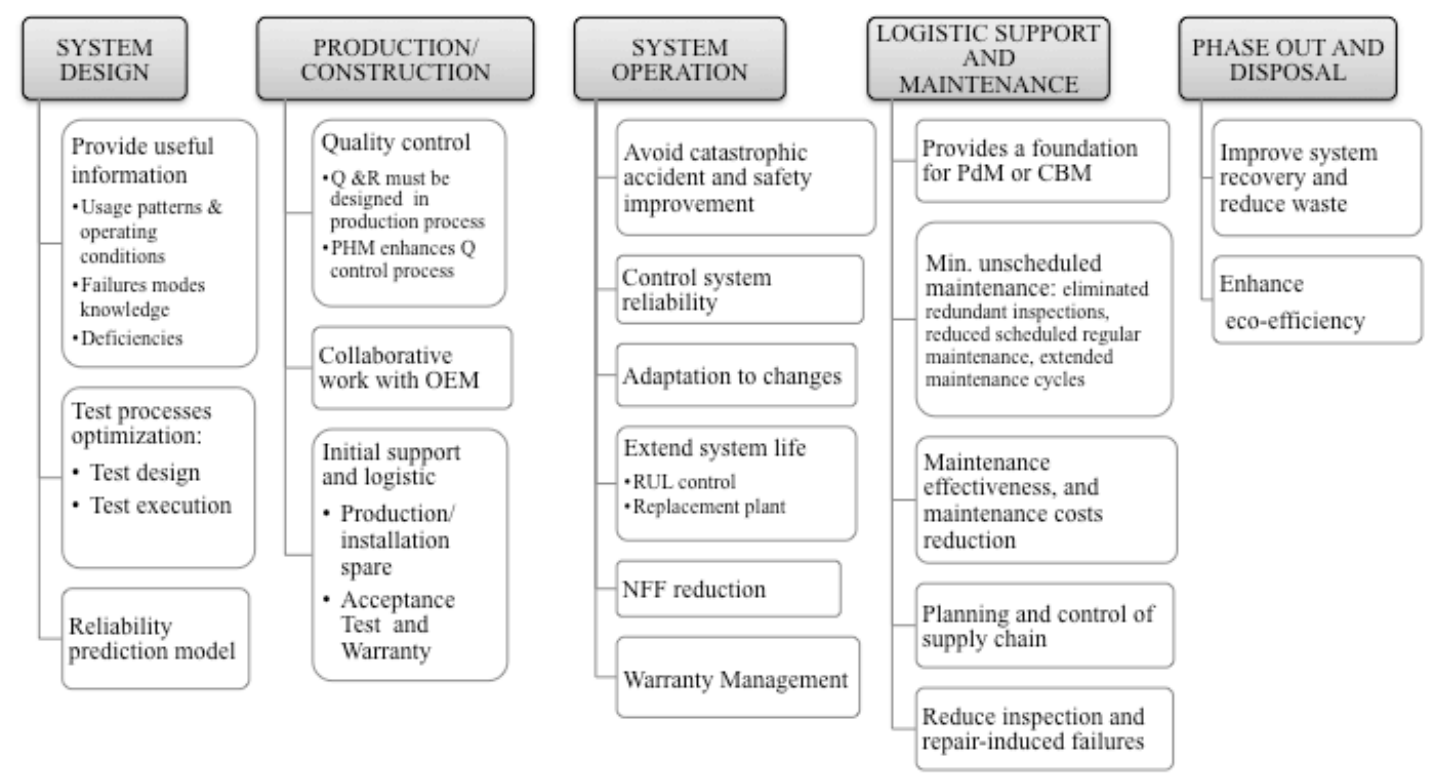

Figure 3. Benefits of PHM along the life cycle phases

It is evident that the benefits regard a large spectrum of stakeholders. Nonetheless, the major benefits can be achieved based on the role of the maintenance function, even if it is necessary to extend the perspective with respect to the classical one. In fact, in their classification, Sun et al (2012) locate operation and maintenance in different phases of the system life cycle: they are focusing on "where" (what phases) those specific benefits appear and can be counted. All the benefits, especially those listed in the system operation and maintenance phase, are still considered a result of maintenance actions. For example, a PHM solution can reduce the risk of a catastrophic accident during system operation. In this case, the losses avoided, that in this type of event usually have very high impact, can be counted as operating benefit provided by the PHM solution; on the other hand, the 
cost and effort of solution design and implementation and, finally, of the operational activities to prevent the accident, will be mostly responsibility of maintenance management. This is a clear evidence of how maintenance practices could extend their scope towards system operation phase, bringing a valuable support for safety through PHM potential, which finally confirms the adoption of PHM as a lever for risk reduction.

PHM is also cornerstone in the development of other research lines, like the aforementioned E-maintenance, or the CPS (Cyber Physical System). CPS are physical and engineered systems whose operations are monitored, coordinated, controlled and integrated by a computing and communication core (Rajkumar et al 2010). Overall, CPS can be considered as adaptive systems with distributed multiple layered feedback loops (Watzoldt S., 2012), where the ability to learn, adapt on new situations can be achieved

through modelling event driven techniques. Trends such as CPS, Smart Manufacturing (Vogl et al. 2014) or Self-Maintenance and Engineering Immune System (Lee et al. 2011), point to a future scenario where the technical content of the equipment, processes, control and management tools, will reach levels well above current standards. In this development the PHM techniques and methods can have a fundamental role and this will reinforce the importance of maintenance in relation to competitiveness of future models of production systems. The very recent vision presented by (Lee et al., 2015) proposes a 5-level structure as an architecture for developing and deploying a CPS for manufacturing application: within it, PHM is introduced at the second level of the CPS architecture to bring "self-awareness" to machines. Owing to the architecture, the advantage envisioned for PHM is the interconnection between machines through an interface at the cyber level, which would help achieving the benefits of a peer-to-peer monitoring and comparisons in fleet of machines: when a cyber-level infrastructure is made available, the machines could operate in a way "conceptually similar to social networks" (Lee et al., 2015) and PHM will play a relevant role with these networks.

\section{The role of PHM within maintenance types and policies}

The incorporation of PHM, as envisioned in previous Section 2, is going to change the way the systems are maintained. To analyze how the PHM capabilities fit within maintenance activities, two complementary perspectives are provided in this section: the relationship of PHM with different types of maintenance are firstly discussed (Section 3.1) before considering the role of PHM within maintenance policies (Section 3.2). Concluding remarks are included as a summary (Section 3.3).

\subsection{PHM and types of maintenance}

According to Section 2, PHM should not be treated as a type of maintenance, as preventive maintenance, condition based maintenance (CBM) or corrective maintenance (see EN 13306). PHM is not a type of maintenance, but a set of tools (techniques and methods) that yield information that can be used as maintenance input. CBM and PdM as further development of CBM - are consolidated terms in industry: to understand how to introduce PHM in maintenance activities it is necessary to clarify the relation with these terms.

Skills and approaches owing to PHM far outweigh classical techniques that have provided support to CBM. So, in order to mark the difference with the classical concept of CBM, some authors or references have tried to introduce new terms to identify and 
distinguish these new techniques and methods from traditional approaches of CBM. In this sense, sometimes the term PHM has been used to designate a new maintenance type based on PHM techniques and methods. With the same aim, new terms such as CBM + (DoD, 2008) or PdM (Predictive Maintenance) (Gupta et al 2012, Wang et al 2007) identifying predictive maintenance with this concept - have been proposed. Vatchsevanos (2006) uses the term CBM/PHM to treat this extended CBM approach.

Regarding predictive maintenance, despite both terms - PHM and predictive maintenance - are closely related, it is necessary to understand their differences. PdM is the part of CBM that is focused on the prediction of failure and prevents the failure or degradation, and it has been used profusely by the industry. This makes sometimes PHM would be identified with predictive maintenance. This is not correct, firstly because the PHM is not a type of maintenance, as it can be deduced from the discussion in previous Section 2; secondly, because PdM can be done without using the PHM techniques and methods, for example it can be actuated based on the experience of the staff.

In conclusion, the type of maintenance that can be performed by using PHM solutions is CBM. In this sense, our vision is that is not necessary to introduce new terms because it can produce confusion or, even worst, the idea that classical techniques are not been useful any more. So we propose to use the expression "CBM enabled by PHM" and the acronym CBM/PHM proposed in Vachtsevanos el al (2006) and adopted also by ADS-79D-HDBK (US Army 2013).

To give a more comprehensive view and clarify the relationship with different types of maintenance, Figure 4 locates on the EN 13306 schema of maintenance types other terms usually adopted by literature: Run To Failure (RTF), Breakdown Maintenance (BM), Usage Based Maintenance (UBM), Time Based Maintenance (TBM), Failure Based Maintenance (FBM), Design-Out Maintenance (DOM) and Detection Based Maintenance (DBM) (Vasseur and Llory, 1999).

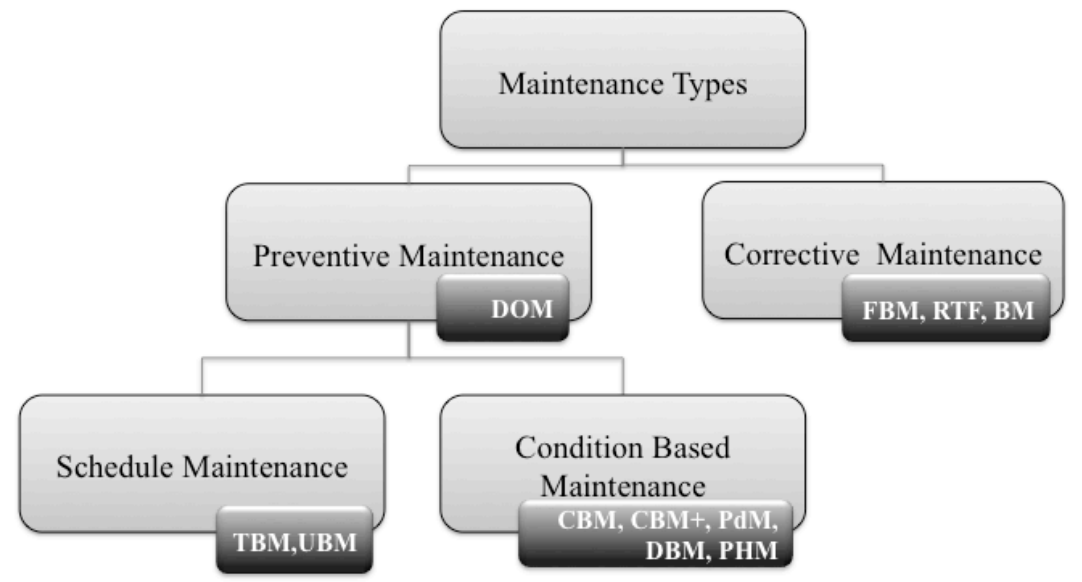

Figure 4. Maintenance types according to EN 13306 and relation with other terms

The trend towards a more proactive maintenance

The transition from a classical CBM to an extended CBM is part of the evolution of maintenance types based on the progressive introduction of new capabilities serving the maintenance function. This evolution is depicted in Figure 5: especially, it shows how this CBM evolution is provided by PHM capabilities; likewise, E-maintenance strategies definitely facilitate a degree of proactivity not achieved so far, as they support greater 
control and capacity to act on the system, including monitoring the efficiency and effectiveness of maintenance plans.

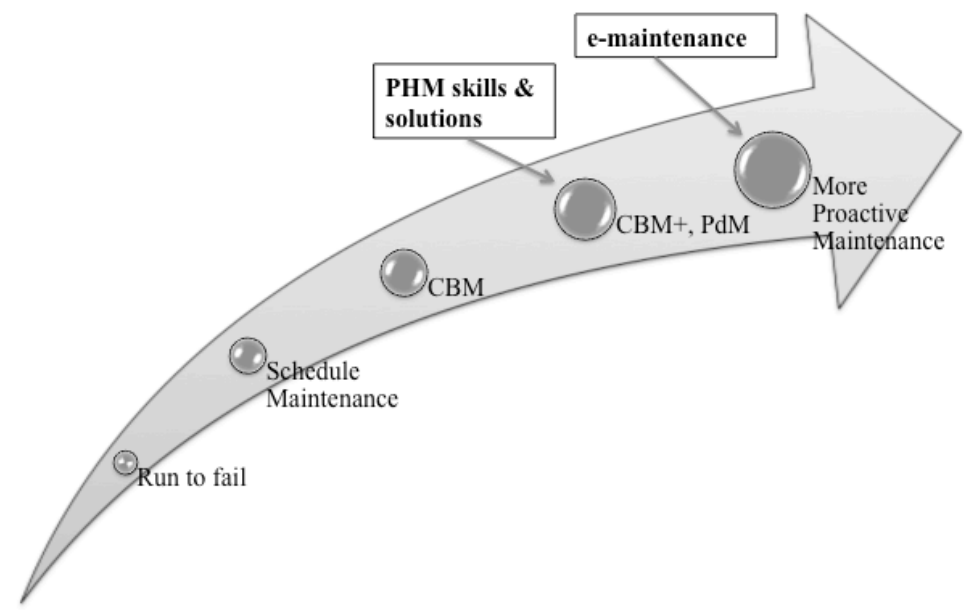

Figure 5. Maintenance types and incorporation of proactive capabilities to the maintenance function

There are two different views about proactivity. Indeed, exploiting the concept of proactivity, a very important part of literature adopts an interpretation about maintenance types that is different to the EN 13306 view mentioned above (Swanson 2001). Moubray (1997) considers two fundamental maintenance types: reactive maintenance (after failure occurs) and proactive maintenance (before failure occurs). Nonetheless, the EN 13306 relates the "corrective maintenance" to the "reactive maintenance" defined by Moubray, and the "preventive maintenance" to what Moubray calls "proactive maintenance".

Adopting the EN 13306 interpretation, as in this paper, makes possible preserving the concept of "proactivity", thus giving to this same concept a wider meaning. We in fact prefer that proactivity in maintenance assumes the meaning of "go beyond" and "do more": not only to prevent the failures and its effects in medium or short term, but also to reach an excellent maintenance management in a continuous improvement process. Swanson (2001) treats similar ideas when she introduces the term of "aggressive maintenance" as strategy that goes beyond the efforts to avoid equipment failures, seeking to improve the overall equipment operation. Likewise, in our concern, the aim would be to get a proactive maintenance, and the "instruments" to get it are the new capabilities providing a better knowledge about systems states and risks (the PHM solutions are providing such new capabilities) and management tools and strategies based on ICTs (incorporated in E-maintenance). With this consideration, the concept of "proactivity" or "proactive maintenance" is actually driving the evolution of maintenance (Lopez-Campos et al. 2013), being PHM and E-maintenance the primary levers of this development (Lee 2006). Within the proactive maintenance trend, one of the main aspects to consider is the ability of maintenance adaptation to the dynamic changes of its requirements (considering different issues as technical and operative aspects, owing to the resources limitation, and aligning to the business strategies and external requirements) along the entire life cycle of the system/asset.

The last step of "proactivity" that can be envisioned for the future scenario (in regard to the trends for CPS, Smart Manufacturing, Engineering Immune Systems, etc.) would lead 
to the integration of PHM and E-maintenance capabilities with operating systems for predictive control strategies. This will enhance the ability to better treat the new system and manufacturing requirements to the maintenance. Indeed, the predictive control (PC) is a research line that is currently creating new opportunities in the field of automation and control: relating it to the maintenance evolution, this would consist of conditioning the basic operation of the system, modifying its control logic according to the observed conditions and estimated RUL. In this way, control decisions impact on efficiency would be accountable, and achievement of excellent performance levels of the system/asset will be possible.

\subsection{PHM and maintenance policies}

The concept of "maintenance policy" according to the IEC 60050-191 will now be used as a framework to facilitate the consideration of PHM within the maintenance function.

The reader may notice that this term, maintenance policy, has had different interpretations or uses in past literature. In some references (Waeyenberg \& Pintelon 2009 ) it is identified with the "type of maintenance" concept defined by EN 13306, i.e. $\mathrm{CBM}$ or TBM are sometimes referred as maintenance policies. At the same time, it is also common to find texts where "maintenance policy" is referred as "maintenance strategy", as defined by EN 13306 (i.e. management method used to achieve the objectives of the maintenance function).

IEC 60050-191 definition of maintenance policy is used in this paper. This standard defines the term of maintenance policy as "a description of the interrelationship between the maintenance echelons, the indenture levels and the levels of maintenance to be applied for the maintenance of an item". This approach is depicted on Figure 6. So, designing the maintenance policy of a system or asset/installation consists on describing the indenture levels (what elements are subject to the maintenance actions), the level of maintenance for each indenture level (what type of maintenance or maintenance action) and the line of maintenance (who is responsible to execute the maintenance tasks). Figure 6 depicts also the relationship between the result of a RCM program and the components of a maintenance policy. This issue is later treated in Section 4. In the next paragraphs of the present section, we review the definition of the different components of a maintenance policy, as given by IEC 60050-191. After clarifying these concepts, according to the standard and offering also examples for their interpretation, PHM will be located in the IEC schema. 


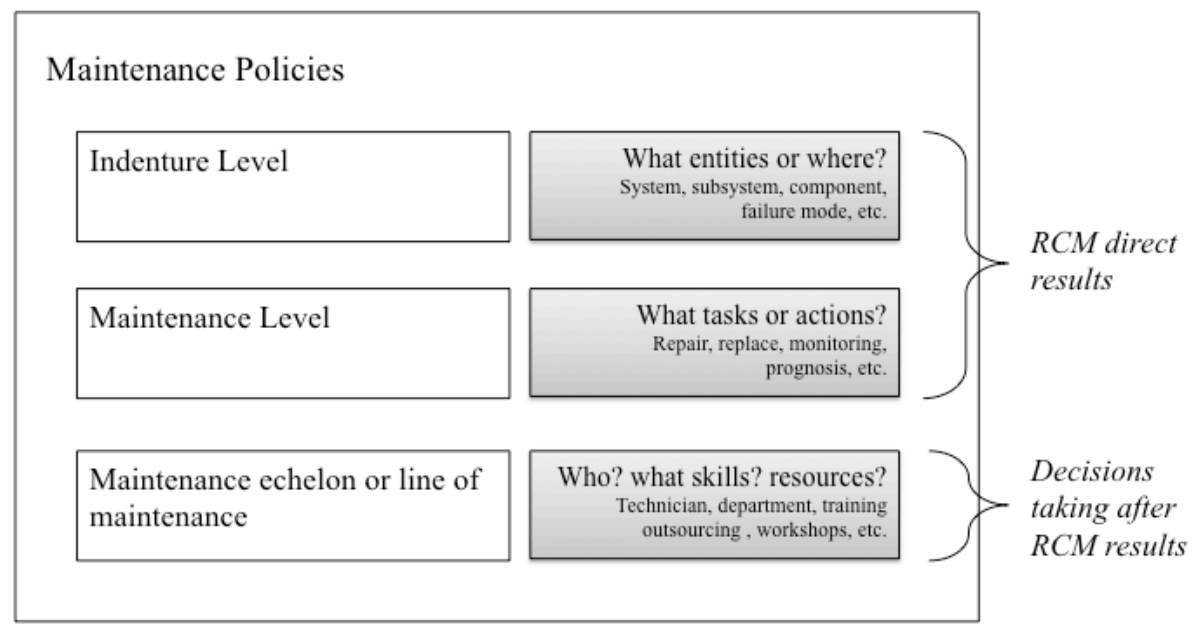

Figure 6. Components of maintenance policy according to IEC 60050-191 and relation of components with the results of a RCM analysis

\section{Indenture Level}

This is the level of decomposition of an item (i.e. system/asset) from the point of view of a maintenance action. Examples of indenture levels could be a subsystem, a circuit board, a component. The indenture level depends on the complexity of the item's construction, the accessibility to sub-items, the skill level of maintenance personnel, the test equipment facilities, safety considerations, etc. For example, in a company without technical capacity for doing corrective maintenance over a circuit board (e.g. repair a certain welding), the indenture level will be established in the next-highest level, defining as maintainable item the element that contains the circuit board (a subsystem as a complete electronic module). The failure mechanism should normally be related to the lowest indenture levels (i.e. maintainable item level). In practical terms, the failure mechanism represents a failure mode at maintainable item level. In this regard, the reader is referred to the standard ISO 14224, as a good guideline to establish proper indenture levels in specific equipment, especially within the oil and gas industry, and considering the business technical structure.

\section{Maintenance level}

This is the set of maintenance actions to be carried out at a specified indenture level. Examples of a maintenance action are replacing a component, a printed circuit board, a subsystem, etc. The level of maintenance is closely related to the application of the RCM logic. At that point of the RCM analysis, the maintenance action over each specific failure mode, as depicted by the FMEA/FMECA, is chosen.

Maintenance echelon or line of maintenance

This is the position in an organization where specified levels of maintenance are to be carried out on a maintainable item. This component of the maintenance policy is not explicitly addressed by the RCM analysis, even if it is implicitly present. Maintenance lines description in fact includes the maintenance resources and their availability. Within a general conception, this component includes material, technical and human resources and required technical knowledge and skills. It is worth noticing how the selection of a particular level of maintenance, for instance a CBM program based on a PHM solution, 
as better maintenance option over a specific failure mode, implicitly requires analyzing whether the organization can offer a suitable support to carry out this action. In this regard, relevant questions may be, e.g.: are existing resources technically capable? Would it be convenient subcontracting?

PHM contributions and requirements for maintenance policies design

To understand how PHM can be introduced as fundamental element for advanced maintenance, it is necessary to get a comprehensive view of how maintenance policies and their components as defined by IEC 60050-191 - are affected by the opportunity or the need of using PHM. PHM solutions are in fact complex and, to manage complexity, a simplified interpretation of maintenance policies, and their use within maintenance design methodologies, can help to understand how PHM can affect the definition and execution of maintenance plans.

One of the main problems to address in the maintenance policies design process is to provide a practical interpretation of the different concepts. Of course, it is important to know different concepts meaning. But at the same time it is also needed to know how to interpret them in the most practical way, combining the accurate definitions with some considerations regarding their application on practical cases. In this sense a simplified view of the components of a maintenance policy can be proposed:

- Indenture level: failure mode definition for each maintainable item;

- Level of maintenance: maintenance types and tasks/actions selected per failure mode;

- Maintenance echelon or line of maintenance: organizational responsibilities, skills and maintenance resources required to accomplish the selected maintenance tasks. Based on this practical interpretation, Table 1 analyses what PHM can provide to each component of the maintenance policy, both in terms of its contributions (provided capabilities) and its requirements (required resources). It is worth pointing out how the specialization of required resources may lead to opportunities for third parties and the use of high-tech tools.

Table 1. PHM contributions and requirements for maintenance policies design 


\begin{tabular}{|c|c|c|}
\hline $\begin{array}{l}\text { Component of the } \\
\text { Maintenance Policy }\end{array}$ & Interpretation & PHM possible contributions and/or requirements \\
\hline Indenture level & $\begin{array}{l}\text { Failure } \\
\text { definition }\end{array}$ & $\begin{array}{l}\text { PHM allows more detailed description of the indenture } \\
\text { level, owing to its capability to provide accurate } \\
\text { information } \\
\text { PHM allows reducing NFF (Not Fault Found) and } \\
\text { similar events } \\
\text { PHM allows reducing hidden failures }\end{array}$ \\
\hline Maintenance level & $\begin{array}{l}\text { Maintenance types, } \\
\text { tasks and/or actions }\end{array}$ & $\begin{array}{l}\text { PHM allows detection, diagnosis and prognosis of a } \\
\text { failure before it occurs } \\
\text { PHM allows to control the failure risk and the } \\
\text { degradation } \\
\text { PHM allows diagnosis after a failure occurs } \\
\text { PHM allows reducing scheduled maintenance } \\
\text { PHM allows effective autonomous maintenance }\end{array}$ \\
\hline $\begin{array}{l}\text { Maintenance echelon } \\
\text { or line of maintenance }\end{array}$ & $\begin{array}{l}\text { Responsibilities, } \\
\text { skills and resources }\end{array}$ & $\begin{array}{l}\text { PHM requires new skills and specialized technicians } \\
\text { PHM requires new technological resources } \\
\text { The shifts of indenture levels definition may introduce } \\
\text { changes in the maintenance skills required by PHM as } \\
\text { well as in the required logistics support (with changes } \\
\text { in the spare parts requirements) } \\
\text { PHM allows to better organize responsibilities for an } \\
\text { effective autonomous maintenance } \\
\text { PHM solutions (design and implementation) can be } \\
\text { subcontracted } \\
\text { PHM solutions can be a service provided by the OEM } \\
\text { (Original Equipment Manufacturer) } \\
\text { PHM can be integrated within E-maintenance tools, } \\
\text { thus supporting the E-maintenance strategies }\end{array}$ \\
\hline
\end{tabular}

\subsection{PHM maintenance types and policies}

Summarizing the role of PHM with respect to the maintenance types and policies, it is worth concluding the following remarks:

- the evolution of maintenance types, based on the progressive incorporation of new capabilities owing to PHM, is leading to more "proactive maintenance";

- maintenance policies will result from properly combining different maintenance levels and lines at different indenture levels; in particular, for a unique system / asset, different maintenance levels can be used for different maintainable items (i.e. maintenance of some items by means of CBM/PHM will be combined with Run-To-Failure in other items).

Thus, using a "proactive maintenance" will designate different matters "to go beyond":

- the maintenance policies are designed and reconfigured, aligning any time with the strategic criteria of the organization and its key strategic factors to achieve competitiveness, profitability and sustainability of the company (eco-efficiency);

- maintenance policy management promotes progressive growth of E-maintenance tools and CBM/PHM solutions; this introduces the chance of greater value added actions, owing to a better understanding of the system and its internal (between 
its component items) and external relations (with other systems / assets, the environment and other maintenance tasks or business areas);

- reconfigurable, adaptive and evolving maintenance policies means facing better and promptly the uncertain evolution of business requirements, the effect of some disruptive events, or even the changing needs along the asset life cycle.

\section{The role of PHM within the RCM framework}

PHM techniques and methods have to be conveniently integrated into the maintenance policies (López-Campos et al. 2013) to exploit their potential. But, as they are complex, their implementation may generate undesirable costs and side-effects to business. Different frameworks or methodologies facilitating design and implementation of maintenance policies (Crespo 2007) can then help to obtain the expected contributions owing to PHM. Although these frameworks consider CBM, none specifically includes the treatment of PHM techniques and methods and the capabilities that these brings to maintenance (Guillen et al 2014), largely owing to the fact that the most used frameworks were developed prior to the recent growth of PHM. To address this lack, in this section the RCM methodology is reviewed analyzing how the use of PHM solutions as part of the maintenance function can be facilitated within a RCM program.

$\mathrm{RCM}$, and its evolutions as RCM II, is one of the main maintenance policies design references. Description of RCM is not the scope of this paper. In case of further wishes to deep on this methodology, it is worth consulting Moubray (1997) or Parra (2012) respectively for what concern RCM and RCM II.

\section{Maintenance policy components, PHM capabilities and RCM process}

Given the definition of maintenance policy in section 3, RCM can be understood as a methodology to define levels of maintenance corresponding to indenture levels of the system / asset to ensure its operational continuity, without occurrence of failure modes in a given operational context. Indeed, the indenture levels are determined when the detailed functional analysis until the possible failure mode of each of the functions is made (FMEA/FMECA); the levels of maintenance are determined by means of the RCM logic. Considering also the organizational aspects, the maintenance lines depend on the maturity of the different actors in each industrial scenario. On the whole, it is possible to link RCM with maintenance policy components as herein illustrated:

- Indenture level: it includes the result of RCM operational context identification and FMEA/FMECA;

- Level of maintenance: it includes the result of RCM logic;

- Maintenance Echelon or line of maintenance: it includes the indirect result of RCM logic in regard to the required skills and resources.

If maintenance policies components are the overall results of a RCM analysis, RCM and PHM have a mutually beneficial relationship helpful to lead to such results. In fact, from a system or equipment perspective, PHM without a RCM analysis becomes just a technology insertion without the justified functionality. Conversely, the collection of aggregated health data, without understanding of the failure modes and most effective course-of-action, can lead to wasted effort and unnecessary expenditure of resources (DoD, 2008). Delving into the areas in which the capabilities of PHM may give support to RCM process steps, the reader is referred to Table 2: the effective achievement of 
results from a RCM analysis, in regard to the maintenance policies components, can be obtained by benefiting from the support of PHM capabilities.

Table 2. CBM/PHM Capabilities and RCM Process Steps (simplified and adapted from DoD, 2008)

\begin{tabular}{|c|c|c|}
\hline RCM phases & RCM process steps & CBM based on PHM enabling capabilities \\
\hline \multirow[t]{5}{*}{ FMEA/FMECA } & $\begin{array}{l}\text { Functions: the desired capability } \\
\text { of the system, how well it is to } \\
\text { perform, and under what } \\
\text { circumstances }\end{array}$ & $\begin{array}{l}\text { Provides analysis and decision support to } \\
\text { determine the maintenance policy to ensure a } \\
\text { required system performance; Provides technical } \\
\text { data to determine optimal resources to perform } \\
\text { maintenance tasks }\end{array}$ \\
\hline & $\begin{array}{l}\text { Functional failures: the failed state } \\
\text { of the system }\end{array}$ & $\begin{array}{l}\text { Provides diagnostic tools to assess degree of } \\
\text { system/component degradation; Tracks health } \\
\text { and status of installed components }\end{array}$ \\
\hline & $\begin{array}{l}\text { Failure modes: the specific } \\
\text { condition causing a functional } \\
\text { failure }\end{array}$ & $\begin{array}{l}\text { Uses sensor and data analysis technology to } \\
\text { identify failure physics; Collects, stores and } \\
\text { communicates system condition and failure data }\end{array}$ \\
\hline & $\begin{array}{l}\text { Failure effects: the description of } \\
\text { what happens when each failure } \\
\text { mode occurs }\end{array}$ & $\begin{array}{l}\text { Uses automated tools and data manipulation } \\
\text { software to produce diagnostic information on } \\
\text { detected failures; Applies information from } \\
\text { Interactive Electronic Technical Manuals to } \\
\text { report, troubleshoot, test, and support } \\
\text { documentation of failures }\end{array}$ \\
\hline & $\begin{array}{l}\text { Failure consequences: the } \\
\text { description of how the loss of } \\
\text { function matters (e.g., safety, } \\
\text { environmental, mission, or } \\
\text { economics) }\end{array}$ & $\begin{array}{l}\text { Maintains platform hardware and software } \\
\text { configuration; Provides data warehouse } \\
\text { capability including condition trends, history, and } \\
\text { transaction records from business processes; } \\
\text { Available to the full range of users. }\end{array}$ \\
\hline \multirow[t]{3}{*}{ RCM logic } & Hidden Failures or NFF events & $\begin{array}{l}\text { Use of new methods and techniques can make } \\
\text { specific types of "hidden failure" no longer being } \\
\text { "hidden" }\end{array}$ \\
\hline & $\begin{array}{l}\text { Maintenance tasks and intervals: } \\
\text { the description of the applicable } \\
\text { and effective tasks, if any, } \\
\text { performed to predict or prevent } \\
\text { failures }\end{array}$ & $\begin{array}{l}\text { Incorporates prognostic capabilities to help } \\
\text { predict failure causes and timing; Predicts the } \\
\text { remaining useful life of equipment/components } \\
\text { based on failure predictors derived from } \\
\text { composite condition analysis; Includes new task } \\
\text { and skills as data gathering task, software } \\
\text { actualization, algorithm configuration, } \\
\text { performance control }\end{array}$ \\
\hline & $\begin{array}{l}\text { Default actions: including but not } \\
\text { limited to failure finding tasks, } \\
\text { run-to-failure, engineering } \\
\text { redesigns, and changes/additions } \\
\text { to operating procedures or } \\
\text { technical manuals. }\end{array}$ & $\begin{array}{l}\text { Supports standard graphics and trending displays, } \\
\text { user alerts, data mining and analysis, simulation } \\
\text { and modeling, enterprise decision-support } \\
\text { systems, and advisory generation. }\end{array}$ \\
\hline
\end{tabular}

\section{Case study}

The case study is a further development of a recent publication aimed at presenting the implementation of an E-maintenance tool in an industrial context. The tool extends the functions of a Supervisory Control and Data Acquisition (SCADA) of an Electric Arc 
Furnace (EAF) for its use in a CBM program (Colace et al., 2015). This paper reports the implementation project held in the real industrial setting of an Italian steel-making company. In particular, it provides a thorough explanation of the methodology adopted during the project to implement the E-maintenance tool, with the final purpose to control the degradation of a specific equipment of the EAF, i.e. the burning system. The reader should consult the publication for more details on the methodology and the equipment under control.

It is worth remarking that safety is a relevant objective of EAF's operations. Furthermore, as the furnace runs continuously at high temperatures and in harsh environmental conditions, inspection of many components can occur when the furnace is stopped for a scheduled maintenance; thus, real-time monitoring capabilities are essential to keep under control the health state of the furnace and its components, in this case the burning system. To this end, the E-maintenance tool extends the functionality of an existent SCADA with state detection and diagnosis (observe that these functions are defined in accordance to the ISO 13374, above discussed in section 2.2). State detection compares the gathered data representing the actual functioning of the burning system against baseline parameters (alias reference values) of flow rates and pressures built in a statistical model, i.e. a regression model ground on field data available from the SCADA. When a deviation from reference values is detected, abnormal events are reported. Afterwards, diagnosis focuses on the failure modes and its causes: the identification of the causes uses a troubleshooting scheme and, subsequently, an advisory generation task is triggered in order to provide the operator with a check-list of operations to perform to solve the causes. The check-list is a list of counteractions defined as outcome of an HAZOP (Hazard and operability analysis) of the burning system (concerning HAZOP studies, see Lawly, 1974 for original definition and guide, and Dunjó J., et al., 2010 for a more recent review).

The conceptual model discussed in the present paper is now illustrated in the context of this case study. Next table 3 shows the PHM contributions (provided capabilities) and requirements (required resources) for maintenance policies design.

Table 3. Case study analysis: PHM contributions and requirements for maintenance policies design 


\begin{tabular}{ll}
\hline $\begin{array}{l}\text { Component of the } \\
\text { Maintenance Policy }\end{array}$ & PHM possible contributions and/or requirements \\
\hline Indenture level & $\begin{array}{l}\text { PHM allows the capability to provide accurate information for the functioning } \\
\text { of the burning system, which is one of the critical equipment for safe and } \\
\text { efficient EAF's operations. }\end{array}$ \\
PHM allows to extend the functionality of the existent SCADA with the \\
capability of detection and diagnosis of a failure of the burning system before \\
it happens. \\
PHM allows to enhance the control of the failure risk and the degradation of the \\
burning system. \\
PHM allows shifting maintenance tasks to the CBM type, thus reducing the \\
interventions based on scheduled maintenance of the burning system. \\
PHM requires to develop some but limited skills for the development, test and \\
setup, and maintenance of the E-maintenance tool. \\
PHM requires new technological resources as a software program whose \\
purpose is to extend the functionality of the SCADA (note that no additional \\
hardware was required in the case, as the measures required for state detection \\
and diagnosis were already available for the production process control). \\
PHM is integrated within the E-maintenance tool, thus providing real-time \\
monitoring extended to a maintenance focus.
\end{tabular}

The CBM/PHM capabilities now available are related to the RCM Process Steps where they are bringing contributions.

Table 4. CBM/PHM Capabilities and RCM Process Steps in the context of the case study

\begin{tabular}{ll}
\hline RCM phases & CBM based on PHM enabling capabilities \\
\hline FMEA/FMECA & Provides a diagnostic tool to assess degradation of the burning system; \\
Tracks, by means of a real-time monitoring, the health state of the burning \\
system; \\
Uses sensor and data analysis technology to identify failure physics; in this \\
regard, it is worth observing that data analysis - by means of a statistical model \\
(i.e. regression model) - is joined with a model-based approach - thanks to \\
HAZOP application, which finally leads to an hybrid diagnostics as data \\
analysis technology; for what concern sensors, field systems required for \\
operations comprise sensors already installed in the plant for production \\
process control, measuring flow rates, pressures and valves position; \\
Collects, stores and communicates system condition data in two ways: a data \\
display conveying, by means of an HMI (Human Machine Interface), \\
dedicated information to the maintenance planner as user; a storage \\
processing, including condition trends and history in a database for future use \\
(i.e. data warehouse capability); \\
Uses automated tools and data manipulation software to produce diagnostic \\
information on detected degradation of failures (it is worth remarking that the \\
implementation is made at different hierarchical levels, as defined by the \\
standard IEC 62264:2003, namely level 1, PLC, and level 2, supervisor \\
computer); \\
Applies information built in as a set of HAZOP tables; in particular, the tables \\
form an Interactive Electronic Technical Manual aiding to report different \\
information in relation to the detected deviations (i.e. causes, effects, \\
counteractions, suggestions, for each deviation resulting from the state \\
detection); this is finally an aid for troubleshooting and, more in general, for \\
\hline
\end{tabular}




\begin{tabular}{ll}
\hline supporting documentation of failures in relationship to the process of the \\
burning system; \\
Includes new task and skills as data gathering task, software actualization, \\
algorithm configuration, in order to support diagnostics of the burning system; \\
Supports standard graphics and trending displays, user alerts, and advisory \\
generation; in particular, the advisory generation provides a check-list, as a set \\
of counteractions derived by the HAZOP tables.
\end{tabular}

The company is nowadays using the tool as part of the automation running the control of the EAF's operations. This is leading to a greater control and capacity to act on the burning system, with the subsequent benefits for process safety and even for further potentials, in next years, towards process improvement thanks to the use of PHM capabilities within the RCM framework.

\section{Conclusions}

The paper has reflected on the role of PHM in maintenance systems. Thus, PHM correspondence with maintenance policies and types has been analyzed. To better distinguish such concepts, the expression "CBM enabled by PHM" (i.e. CBM/PHM) was considered. This enabled to remark that new technical capabilities have been added to the maintenance function, supported by PHM. It is precisely these new capabilities that open the door to a large room for improvement in terms of competitiveness and profitability: PHM, within E-maintenance strategies, are in fact seen as key points for competitiveness in the future, providing the basis for proactive maintenance management.

PHM impact on maintenance policies can modify levels and lines of maintenance (changing the actions that can be executed on a system and defining who runs the actions). The information actually available by PHM may also modify the assets indenture levels for maintenance definition, and may even render new maintenance actions convenient, contributing to extend the levels of maintenance. Afterwards, it is also important to use the existing methodologies for the design and implementation of maintenance policies: it is indeed essential to consider the capabilities of CBM/PHM in the development of a RCM process, especially in high-tech complex engineering systems, for full exploitation of the PHM potential.

On the whole, the paper provides a handy synthesis of the PHM potential into a framework for a system maintenance management: in fact, we believe that the research finding will contribute fixing the role of PHM in relationship to consolidated matters as the maintenance policies design and RCM framework. For the future work, we consider, as first priority, the need to operationalize the integration of RCM process steps with CBM/PHM capabilities; a second, more advanced issue would be the integration of PHM and E-maintenance capabilities with operating systems for predictive control strategies, which is in line with the expected trends for CPS, Smart Manufacturing, etc.

\section{Acknowledgement}

This research work was performed within the context of SustainOwner ('Sustainable Design and Management of Industrial Assets through Total Value and Cost of Ownership'), a project sponsored by the EU Framework Programme Horizon 2020, 
MSCA-RISE-2014: Marie Skłodowska-Curie Research and Innovation Staff Exchange (RISE) (grant agreement number 645733 - Sustain-Owner - H2020-MSCA-RISE2014).

\section{References}

Bird, J., Madge, N., Reichard, K., 2014. Towards a Capabilities Taxonomy for Prognostics and Health Management; International Journal of Prognostics and Health Management, 2014, 2.

Cheng, S., Azarian, M., Pecht, M., 2010. Sensor Systems for Prognostics and Health Management, Sensors, 10, 5774-5797.

Crespo, A., Gupta, J., 2006. Contemporary maintenance management: process, framework and supporting pillars. Omega 2006;34(3): 313-26.

Crespo, A., Moreu, P., Sola, A., Gómez, J., 2015. Criticality Analysis for Maintenance Purposes. Quality and Reliability Engineering international. In Print.

Department of Defense (USA), 2008. Condition Based Maintenance Plus, DoD Guidebook.

Dunjó J., Fthenakis V., Vílchez J.A., Arnaldos J., 2010. Hazard and operability (HAZOP) analysis. A literature review. J Hazard Mater, 173(1-3), 19-32.

European Committee for Standadization. EN13306: 2010. Maintenance Terminology. Brussels

Ferrell, B. L., 1999. JSF Prognostics and Health Management. Proceedings of IEEE Aerospace Conference. March 6-13, Big Sky, MO. doi: 10.1109/AERO.1999.793190

Fritzsche, R., Gupta, J., Lasch, R., 2014. Optimal prognostic distance to minimize total maintenance cost: The case of the airline industry, International Journal of ProductionEconomics, 151, 76-88

Garetti, M., Taisch, M., 2012. Sustainable manufacturing: trends and research challenges. Production Planning and Control, Volume 23, Issue 2-3, , 83-104.

Gómez, J., Crespo, A., 2012, Maintenance Management in Network Utilities, framework and practical implementation, Springer-Verlag, London

Guillén, A.J., Gómez, J., Crespo, A., Guerrero A., 2014. Towards the Industrial Application of PHM: Challenges and Methodological Approach, PHM Society European Conference 2014.

Gupta, J., Trinquier, C., Lorton, A., Feuillard, V., 2012. Characterization of prognosis methods: an industrial approach, European Conference of the Prognostics and Health Management Society, 2012.

Haddad, G., Sandborn, P., Pecht, M., (2012). An Options Approach for Decision Support of Systems with Prognostic Capabilities, IEE Transactions on Reliablity, Vol 61, no. 4, December 2012.

International Electrotechnical Commission, 1990. IEC 60051-901, International Electrotechnical Vocabulary -part 191: Dependability and quality of service. 
International Electrotechnical Commission, 2003. IEC 62264, Enterprise-control system integration.

International Electrotechnical Commission, 2006. IEC 60812 - Analysis techniques for system reliability - Procedure for failure mode and effects analysis (FMEA)

International Organization for Standardization, 2003. ISO 13374-1:2003 - Condition monitoring and diagnostics of machines - Data processing, communication and presentation - Part 1: General guidelines

International Organization for Standardization, 2007. ISO 13374-2:2007 - Condition monitoring and diagnostics of machines - Data processing, communication and presentation - Part 2: Data processing

International Organization for Standardization, 2012b. ISO 13379-1:2012 - Condition monitoring and diagnostics of machines - Data interpretation and diagnostics techniques - Part 1: General guidelines

Jardine, A., Lin, D., Banjevic, D., 2006. A review on machinery diagnostics and prognostics implementing condition based maintenance, MechSyst Signal Process; 20:1483-1510.

Lawley, H.G., 1974. Operability studies and hazard analysis, Chem Eng Prog, 70(4), 4556.

Lee, J., Lapira, E., Bagheri, B., Kao, H., 2013. Recent advances and trends in predictive manufacturing systems in big data environment, Manufacturing Letters, 1 (1), 3841

Lee, J., Bagheri, B., Kao, H., 2015. A Cyber-Physical Systems architecture for Industry 4.0-based manufacturing systems. Manufacturing Letters, Volume 3, 18-23.

Lee, J., Ghaffari, M., Elmeligly, S., 2011. Self-maintenance and enginering inmune systems: towards smarter machines and manufacturing systems. Annual Reviews in Control, 35, 111-122.

Lee, J., Ghaffari, M., Elmeligy, S., 2011. Self-maintenance and engineering immune systems: Towards smarter machines and manufacturing systems, Annual Reviews in Control, 35, 111-122

Lee, J., Holgado, M., Kao, H, Macchi, M., 2014. New Thinking Paradigm for Maintenance Innovation Design, in Proceedings of the 19th IFAC World Congress, Cape Town, South Africa, IFAC Proceedings Volumes (IFAC-Papers Online), 24-29.

Lee, J., Ni, J., 2014. Infotronics-based intelligent maintenance system and its impacts to closed-loop product life cycle systems. Invited keynote paper for IMS'2004International conference on intelligent maintenance systems, Arles, France.

Lee, J., Ni, J., Djurdjanovic, D., Qiu, H., Liao, H., 2006. Intelligent prognostics tools and e-maintenance, Computers in Industry , 57, 476-489

Levrat, E., Iung, B. and Crespo A., 2008. E-maintenance: review and conceptual framework, Production Planning and Control, Volume 19, Issue 4, 408-429.

López-Campos, M., Crespo, A., Gómez, J.F., 2013. Modelling using UML and BPMN the integration of open reliability, maintenance and condition monitoring management systems: An application in an electric transformer system. Computers in Industry, 64, 524-542. 
Ly, C., Tom, K., ByingtonC.S., Patrick, R., Vatchsevanos, G. J., 2009. Fault Diagnosis an Failure Prognosis on Engeneering System: a Global Perspective. 5th Annual IEEE Conference on Automation Science and Engineering, Bangalore,

Macchi, M., Crespo, A., Holgado, M., Fumagalli, L., Barberá, L., 2014. Value-driven engineering of E-maintenance platforms. Journal of Manufacturing Technology Management, Volume 25, Issue 4, 568-598.

Macchi, M., Fumagalli, L., 2013. A maintenance maturity assessment method for the manufacturing industry. Journal of Quality in Maintenance Engineering, Volume 19, Issue 3, 295-315.

MIMOSA (Machinery Information Management Open Standards Alliance), 2006. Open Systems Architecture for Condition BasedMaintenance (OSA-CBM) UML Specification, v3.1,

Moubray, J., 1997. RCM II: Reliability-centred Maintenance. New York: Industrial Press Inc.

Muller, A., Crespo, A., Iung, B. 2008. On the concept of e-maintenance: Review and current research, Reliability Engineering and System Safety, 93, 1165-1187

Parra, C,. Crespo, A., 2012. Maintenance Engineering and Reliability for Assets Management. Ingeman.

Pecht, M., 2008. Prognostics and Health Management of Electronics. Hoboken, NJ: Wiley, 2008.

Pecth, M., Rubyca, J., 2010. A prognostics and health management roadmap for information and electronics-rich systems, Microelectronics Reliability , 50, $317-$ 323.

Pinjala, S., Pintelon, L., Vereecke, A., 2006. An empirical investigation on the relationship between business and maintenance strategies. International Journal of Production Economics, 104 (1), 214-229

Rajkumar R., Lee I., Sha L., Stankovic J. 2010, Cyber-physical systems: The next computing revolution, Proceedings - Design Automation Conference 2010, 731736

Saxena, A., Roychoudhury, I. , Celaya, J.R., Saha, S., Saha, B. , Goebel, K., 2010. Requirements specifications for prognostics: An overview. AIAA Infotech at Aerospace 2010, art. no. 2010-3398

Saxena, A., Celaya, J., Saha, B., Saha, S., Goebel, K., 2010. Metrics for Offline Evaluation of Prognostic Performance International Journal of Prognostics and Health Management, 1.

Sheppard, J., Kaufman, K, Wilmering, T., 2008. IEEE Standards for Prognostics and Health Management, IEEE AUTOTESTCON 2008

Sun, B., Zeng, S., Kang, R., Pecht, M., 2012. Benefits and Challenges of System Prognostics, IEEE Transaction on Reliability, 61 (2).

Swanson, L., 2001. Linking maintenance strategies to performance. International Journal of Production Economics, 70 (3), 237-244.

Tobon-Mejia, D., Medjaher, K. 2010. IEEE Prognostics \& System Health Management Conference, PHM'2010., Macau (China) 
United States Army, 2013. ADS-79D-HDBK - Aeronautical Design Standard Handbook for Condition Based Maintenance Systems for US Army Aircraft

Vachtsevanos, G., Lewis, F., Roemer M., Hess A., Wu B. 2006, Intelligent Fault Diagnosis and Prognosis for Engineering Systems.Hoboken, NJ, John Wiley and Sons.

Waeyenbergh, G., Pintelon, L., 2002. A framework for maintenance concept development. International Journal of Production Economics 77, 299-313

Waeyenbergh, G.,Pintelon,L.,2009. CIBOCOF: a framework for industrial maintenance concept development. International Journal of Production Economics 121, 6336402009.

Waeyenbergh, W., Pintelon,L., 2004. Maintenance concept development: a case study. International Journal of Production Economics 89,395-405.

Wang, L., Chu, J.a , Wu, J., 2007. Selection of optimum maintenance strategies based on a fuzzy analytic hierarchy process. International Journal of Production Economics, 107 (1), 151-163.

Watzoldt, S., 2012. HPI Symposium 2012: "Reconfiguration in Cyber-Physical Systems". URL: http://www.hpi.uni potsdam.de/fileadmin/hpi/FG_Giese/Slides/waetzoldt_SAP_17_1 2_2012.pdf 